\title{
Comparison investigation on the load capacity of octagonal, circular and square concrete filled steel tubes
}

\begin{abstract}
J-Y. Zhu and T-M. Chan
The Hong Kong Polytechnic University, Hung Hom, Hong Kong

Department of Civil and Environmental Engineering

*T.M. Chan, e-mail address: tak-ming.chan@polyu.edu.hk

Abstract

This paper presents a comparative investigation on the load capacity of octagonal concrete filled steel tubes (CFST) with that of the commonly used circular and square CFST. Existing experimental data of octagonal CFST were collected and based on the crosssectional properties of the existing octagonal specimens, the corresponding circular and square cross-section were generated under three different control parameters: total crosssectional area of column, confinement ratio and axial stiffness. Those circular and square cross-sections were used in the numerical analysis of CFST to obtain the load capacity for the comparative investigation. Validated finite element models were built for the modeling of the circular and square CFST. The outcome of comparison shows that the confinement ratio is the crucial parameter to the difference of axial behaviour between octagonal and circular CFST. Under the same confinement ratio, octagonal CFST has a very close axial bearing performance to that in circular CFST and are much better than the square CFST.
\end{abstract}

Keywords: concrete filled steel tubes; cross-section shape; confinement.

\section{Introduction}

Concrete filled steel tube (CFST) have shown its superiority against axial compressive load. The strength of concrete can be enhanced by the confinement from steel tube and the concrete core could delay the appearance of local buckling of steel tube. Many studies [1-3] have indicated that the confinement in CFST is related to the following parameters: confinement ratio, concrete grade and cross-section shapes. Among them, cross-section shapes of CFST have a great impact on the confinement effectiveness where the commonly used circular section has higher benefits from confinement for the compressive resistance of CFST than its counterparts rectangular CFST. The poor axial bearing performance of rectangular CFST is caused by the sharp corner which lead to a stress concentration at corner region while the confinement in flat side are insufficient. However, the flat side of rectangular CFST can provide an easier solution for the beam-column connection with an endplate. To achieve both the structural efficiency and constructability of CFST, octagonal section is suggested which has a better confinement effectiveness and flat column sides [2, 4]. Experimental investigations have been done on the octagonal CFST to explore the potentials in the effect of confinement $[2,5,6]$. However, the existing literature only presented a general comparison between circular, octagonal and square CFST, no investigations have presented a consistent comparison with control parameters from the cross-section properties to show the actual difference of load bearing capacity in those three different cross-sections.

In this paper, a comparative investigation on the load capacity of octagonal, circular and square CFST were conducted. The data of load capacity of octagonal CFST were collected from the existing experimental results while the data of corresponding circular and square CFST in the comparison were generated by a validated finite element models. This investigation devotes to establish a complete understanding on the difference in the load capacity of octagonal CFST compared with those CFST with commonly used cross-section shapes. 


\section{Existing experimental data}

Existing experimental results on octagonal CFST have been collected and shown in Table 1. The collected results have the concrete cylinder strength $f_{\text {co }}$ ranges from $32 \mathrm{MPa}$ to $100 \mathrm{MPa}$, which covers both normal strength concrete and high strength concrete. However the steel material only covers mild steel with yield stress $f_{\mathrm{y}}$ from 296 to $311 \mathrm{MPa}$ as no experimental studies have conducted on the octagonal CFST with high strength steel. The width to thickness ratio $b / t$ ranges from 21 to 52 which are within the suggested limit in Eurocode 4 [7] to resist the local buckling of the steel tubes before yielding of material. Confinement ratio $\xi$ is defined as:

$\xi=\frac{A_{s} f_{y}}{A_{c} f_{c o}}$

where $A_{\mathrm{s}}$ and $A_{\mathrm{c}}$ are the cross-sectional area of steel tube and concrete core respectively.

Table 1. Experimental results on octagonal CFST.

\begin{tabular}{lccccc}
\hline Reference & Spec. & $\begin{array}{c}\boldsymbol{f}_{\boldsymbol{c o}} \\
\mathrm{MPa}\end{array}$ & $\begin{array}{c}\boldsymbol{f}_{\mathbf{y}} \\
\mathrm{MPa}\end{array}$ & $\boldsymbol{b} / \boldsymbol{t}$ & $\boldsymbol{\xi}$ \\
\hline Ding et al. & 8 & $32-$ & $311-$ & $33-$ & $0.23-$ \\
[5] & & 46 & 321 & 52 & 0.52 \\
Zhu and & 2 & 100 & 296 & 21 & 0.28 \\
Chan [6] & & & & & \\
\hline
\end{tabular}

\section{Comparative investigation}

The change of the cross-section shapes changes many other parameters such as crosssectional area, confinement ratio and crosssectional stiffness. To present a consistent comparative investigation on the load capacity from octagonal, circular and square CFST in engineering and practical perspective control parameters should be defined. Three groups of comparison with different control parameters which may be considered in practical application were presented. In the comparisons, data of the octagonal CFST were collected from the existing literature which is illustrated in Table 2 and based on the geometrical properties of the octagonal specimens, the corresponding circular and square cross-section were generated. Finite element models of circular and square CFST with specified sectional dimension were established for the comparison.

\section{Comparison 1:}

In this group, the control parameter is confinement ratio $\xi$ which also can reflect the steel contribution in the composite cross-section. This group of comparison is to examine the confinement effectiveness of each section under the same confinement ratio. It was found that under the same material contribution ratio the cross-sectional area of each section is different.

\section{Comparison 2:}

In this group, the cross-sectional area was selected as the control parameter. It should be noted that the different confinement ratio was found in this group of comparison. With the same cross-sectional area, the square section gives the highest confinement ratio then follows by the octagonal section and the circular crosssection shows the lowest ratio.

\section{Comparison 3:}

In this approach, the control value is the axial stiffness, $(E A)_{s c}$, of the cross-section.

$$
(E A)_{s c}=E_{s} A_{s}+E_{c} A_{c}
$$

This approach is for those design applications where the stiffness of the column is required.

Table 2. Cross-sectional properties of octagonal specimens from existing experimental result.

\begin{tabular}{|c|c|c|c|c|c|}
\hline Specimen & $\begin{array}{c}\boldsymbol{f}_{\boldsymbol{y}} \\
\mathrm{MPa}\end{array}$ & $\begin{array}{c}f_{c o} \\
\mathrm{MPa}\end{array}$ & $\begin{array}{c}\boldsymbol{A}_{\boldsymbol{s c}} \\
\mathrm{mm}^{2} \\
\times 10^{3}\end{array}$ & $\xi$ & $\begin{array}{c}(\boldsymbol{E} \boldsymbol{A})_{s c} \\
\mathrm{kN} \\
\times 10^{5}\end{array}$ \\
\hline \multicolumn{6}{|c|}{ Ding et al. 2016 [5] } \\
\hline OST1-A & 311 & 32 & 195 & 0.32 & 63.4 \\
\hline OST1-B & 311 & 32 & 191 & 0.33 & 62.7 \\
\hline OST2-A & 321 & 32 & 193 & 0.52 & 68.4 \\
\hline OST2-B & 321 & 32 & 188 & 0.52 & 66.3 \\
\hline OST3-A & 311 & 46 & 193 & 0.22 & 73.0 \\
\hline OST3-B & 311 & 46 & 191 & 0.23 & 72.6 \\
\hline OST4-A & 321 & 46 & 188 & 0.36 & 75.7 \\
\hline OST4-B & 321 & 46 & 190 & 0.36 & 76.7 \\
\hline \multicolumn{6}{|c|}{ Zhu and Chan (2017)[6] } \\
\hline O-CF-1 & 296 & 100 & 17 & 0.25 & 9.17 \\
\hline $\mathrm{O}-\mathrm{CF}-2$ & 296 & 100 & 17 & 0.25 & 9.17 \\
\hline
\end{tabular}

\section{Finite element analysis}

\subsection{Model description}

A finite element (FE) analysis was conducted with the use of the commercial software package ABAQUS. A simple stress-strain model of steel material, which will be introduced in the following sections, was used to determine the 
properties of steel tube. Four-node shell element with reduced integration, S4R was used in the analysis. Ellobody and Young [9] and Thai et al. [10] have successfully adopted this type of element in FE model circular and square CFST under axial compression. Eight-node solid element, C3D8R, in ABAQUS was adopted for the concrete [8]. The boundary condition at the bottom surface of the model was constrained in all degrees of freedom to replicate fix-fix end. The top surface of the column including both steel tube and concrete core were coupled to a reference point, which was also constrained in all degree of freedom except loading direction. Load was applied to the reference point by imposing an axial displacement. Mesh convergence study was conducted to determine the appropriate mesh configuration. The surfaceto-surface contact with a friction coefficient $\mu=0.3$ [6] was used between the inner surface of steel tube and concrete surface.

\subsection{Steel material}

A simple bilinear stress-strain model instead of the elastic, perfectly plastic material model was used in the finite element modeling to reflect the strain hardening of the material. The stressstrain relationship is shown as follows:

$$
\begin{aligned}
& \sigma_{s}=\left\{\begin{array}{cc}
E_{s} \varepsilon_{s} & \varepsilon_{s}<\varepsilon_{y} \\
f_{y}+E_{s h}\left(\varepsilon_{s}-\varepsilon_{y}\right) & \varepsilon_{s}>\varepsilon_{y}
\end{array}\right. \\
& \varepsilon_{y}=\frac{f_{y}}{E_{s}} \\
& E_{s h}=\frac{E_{s}}{100}
\end{aligned}
$$

where $\sigma_{s}$ and $\varepsilon_{s}$ are, respectively, the stress and strain of steel tube. True stress and the plastic strain were generated from the engineering stress-strain relationship and were used in the finite element modeling.

$$
\begin{aligned}
& \sigma_{s, t}=\sigma_{s}\left(1+\varepsilon_{s}\right) \\
& \varepsilon_{p}=\ln (1+\varepsilon)-\sigma_{s, t} / E_{s}
\end{aligned}
$$

where $\sigma_{s, t}$ is the true stress of steel material and $\varepsilon_{p}$ is the plastic strain. The option *PLASTIC model provided by ABAQUS was adopted to model the plastic behaviour of steel.

\subsection{Concrete material}

The adopted concrete constitutive model for CFST was firstly proposed by Han et al. [11] and then further introduced in Han et al. [8]. It was indicated that this model covers the confined concrete in circular and rectangular CFST with a confinement ratio, $\xi$ from 0.2 to 5 and concrete cylinder strength ranges from 24 to $100 \mathrm{MPa}$. The stress-strain model is shown as follows:

$$
\begin{aligned}
& \frac{\sigma}{f_{c o}}= \begin{cases}2\left(\varepsilon / \varepsilon_{o}\right)-\left(\varepsilon / \varepsilon_{o}\right)^{2} & \varepsilon / \varepsilon_{o} \leq 1 \\
\frac{\left(\varepsilon / \varepsilon_{o}\right)}{\left[\beta\left(\varepsilon / \varepsilon_{o}-1\right)^{\eta}+1\right]} & \varepsilon / \varepsilon_{o}>1\end{cases} \\
& \varepsilon_{o}=\varepsilon_{c o}+800 \xi^{0.2} 10^{-6}
\end{aligned}
$$

For circular section:

$\eta=2$

$\beta=\left(2.36 \times 10^{-5}\right)^{\left[0.25+(\xi-0.5)^{7}\right]}\left(f_{c o}\right)^{0.5} \times 0.5$

For rectangular section:

$\eta=1.6+1.5 /\left(\varepsilon / \varepsilon_{o}\right)$

$\beta=\left(f_{c o}\right)^{0.1} /(1.2 \sqrt{1+\xi})$

where $\sigma_{c}$ and $\varepsilon_{c}$ are the stress and strain of concrete core, respectively. The Concrete Damaged Plasticity Model (CDPM) provided by ABAQUS was used to model the behaviour of confined concrete. The flow potential eccentricity, viscosity, the strength ratio of concrete between biaxial compression and uniaxial compression, $f_{b o} / f_{c o}$, are shown as:

Flow potential eccentricity $=0.1$;

Viscosity $=0$;

$f_{b o} / f_{c o}=1.16$.

The ratio of the second stress invariant on the tensile meridian to that on the compressive meridian $K$, and dilation angle $\psi$ are adopted from the equation in Tao et al. [12] where

$$
\begin{aligned}
& K=\frac{5.5}{5+2 f_{c o}^{0.075}} \\
& \psi= \begin{cases}56.3(1-\xi) & \xi \leq 0.5 \\
6.672 e^{\frac{7.4}{4.64+\xi}} & \xi>0.5\end{cases}
\end{aligned}
$$




\subsection{Validation}

Experimental results from Han et al. [8] were used for the validation of the current finite element analysis. The validation results are shown in Table 3. It could be found that the finite element analysis can well captured the load capacity of the circular and square CFST.

Table 3. Cross-sectional properties of octagonal specimens from existing experimental result.

\begin{tabular}{cccccc}
\hline Specimen & $\begin{array}{c}\boldsymbol{D} / \boldsymbol{b} \\
\mathrm{mm}\end{array}$ & $\begin{array}{c}\boldsymbol{t} \\
\mathrm{mm}\end{array}$ & $\begin{array}{c}\boldsymbol{f}_{\boldsymbol{y}} \\
\mathrm{MPa}\end{array}$ & $\begin{array}{c}\boldsymbol{f}_{\text {co }} \\
\mathrm{MPa}\end{array}$ & $\boldsymbol{N}_{\boldsymbol{f e}} / \boldsymbol{N}_{\text {test }}$ \\
\hline CCFST & & & & & \\
\hline CA1-1 & 60 & 1.87 & 282 & 70 & 1.05 \\
CA2-1 & 100 & 1.87 & 282 & 70 & 0.95 \\
CB2-1 & 100 & 2 & 404 & 70 & 1.02 \\
AVG & & & & & 1.01 \\
\hline SCFST & & & & & \\
\hline SB2-1 & 100 & 2 & 404 & 41 & 0.96 \\
SB3-1 & 150 & 2 & 404 & 41 & 0.98 \\
SA2-1 & 100 & 1.87 & 282 & 65 & 0.99 \\
AVG & & & & & 0.97 \\
\hline
\end{tabular}

where $D$ is the diameter of circular section and $b$ is the width of the square section. Fig. 1 shows the failure modes of the validated FE models.
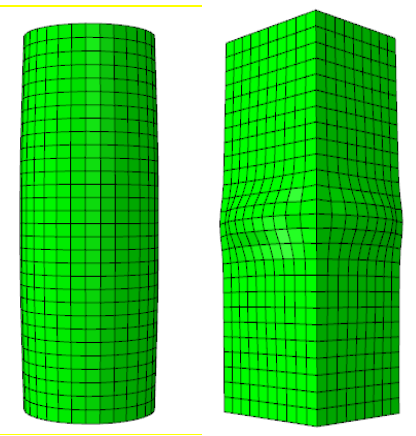

Fig. 1. Failure mode of specimen CA1-1 (left) and SB2-1 (right).

\section{Result of comparative investigation}

The introduced finite element modeling technique was adopted to establish 60 finite element models of CFST with the circular and square cross-section as specified in the three comparison groups. The modeling results were compared with the experimental data of octagonal CFST. As the cross-sectional area may affect the magnitude of load bearing capacity, the overall stress of the composite section $f_{\text {sc }}$ was used in the comparison.

$$
f_{s c}=\frac{N_{s c}}{A_{c}+A_{s}}
$$

where $N_{s c}$ is the load capacity of the crosssection. In addition, the overall stress of octagonal CFST collected from experimental investigation was defined as a reference value. The corresponding numerical results from circular and square CFST were normalized base on the reference.

\subsection{Comparison 1}

In this group, the control parameter was confinement ratio. Table 4 shows the results where $f_{s c, o}, f_{s c, c}$ and $f_{s c, s}$ are the overall stress of octagonal, circular and square CFST. Consistent results show that with the same confinement ratio or level of steel contribution, the axial bearing performance of octagonal CFST and circular CFST are almost identical and both better than that in square CFST. It is because the poor confinement effectiveness significantly decreases the enhancement in load capacity of the square CFST. The difference is up to $20 \%$.

Table 4.Comparison between CFSTs with same cross-sectional area.

\begin{tabular}{|c|c|c|c|c|c|c|}
\hline \multirow[b]{2}{*}{ Specimen } & \multicolumn{2}{|c|}{ OctCFST } & \multicolumn{2}{|c|}{$C C F S T$} & \multicolumn{2}{|c|}{ SCFST } \\
\hline & $\begin{array}{c}\boldsymbol{A}_{\boldsymbol{s c}} \\
\mathrm{mm}^{2} \\
\times 10^{3} \\
\end{array}$ & $\begin{array}{l}f_{s c, o} \\
f_{s c, o}\end{array}$ & $\begin{array}{c}\boldsymbol{A}_{\boldsymbol{s c}} \\
\mathrm{mm}^{2} \\
\times 10^{3}\end{array}$ & $\begin{array}{c}f_{s c, d} \\
f_{s c, o}\end{array}$ & $\begin{array}{c}\boldsymbol{A}_{\boldsymbol{s c}} \\
\mathrm{mm}^{2} \\
\times 10^{3} \\
\end{array}$ & $\begin{array}{l}f_{s c, \mathbb{d}} \\
f_{s c, o}\end{array}$ \\
\hline \multicolumn{7}{|c|}{ Ding et al. $2016[5]$} \\
\hline OST1-A & 195 & 1.00 & 185 & 1.00 & 236 & 0.85 \\
\hline OST1-B & 191 & 1.00 & 182 & 0.99 & 231 & 0.84 \\
\hline OST2-A & 193 & 1.00 & 184 & 1.09 & 234 & 0.88 \\
\hline OST2-B & 188 & 1.00 & 178 & 1.00 & 227 & 0.80 \\
\hline OST3-A & 193 & 1.00 & 183 & 0.98 & 233 & 0.82 \\
\hline OST3-B & 191 & 1.00 & 182 & 0.99 & 231 & 0.83 \\
\hline OST4-A & 188 & 1.00 & 178 & 0.99 & 227 & 0.87 \\
\hline OST4-B & 190 & 1.00 & 180 & 1.00 & 229 & 0.85 \\
\hline \multicolumn{7}{|c|}{ Zhu and Chan (2017)[6] } \\
\hline $\mathrm{O}-\mathrm{CF}-1$ & 17 & 1.00 & 16 & 1.01 & 21 & 1.02 \\
\hline $\mathrm{O}-\mathrm{CF}-2$ & 17 & 1.00 & 16 & 0.99 & 21 & 0.99 \\
\hline
\end{tabular}

\subsection{Comparison 2}

In this group, the control parameter was cross-sectional area. Table 5 shows the results of comparison between CFSTs with same crosssectional area. It could be found that with the same cross-sectional area the axial bearing performance of square CFST is lower than that from octagonal CFST and circular CFST even with a larger confinement ratio. The difference in the performance of circular and octagonal CFST depends on the changes of the confinement ratio. Fig. 2 illustrate the relationship of confinement ratio and the normalized axial stress of the circular and 
octagonal CFST. As the confinement ratio in octagonal CFST increased, the difference in the axial bearing capacity become significant compared with that in circular CFST. It should be noted that at low level of confinement ratio, the axial performance of octagonal CFST is even better than that in circular CFST with same cross-sectional area.

Table 5. Comparison between CFSTs with same material contribution ratio.

\begin{tabular}{ccccccc}
\hline & \multicolumn{2}{c}{$\boldsymbol{O c t C F S T}$} & \multicolumn{2}{c}{$\boldsymbol{C C F S T}$} & \multicolumn{2}{c}{$\boldsymbol{S C F S T}$} \\
\cline { 2 - 7 } Specimen & $\boldsymbol{\xi}$ & $\begin{array}{c}\boldsymbol{f}_{\boldsymbol{s c}, \boldsymbol{o}} / \\
\boldsymbol{f}_{\boldsymbol{s c}, \boldsymbol{o}}\end{array}$ & $\boldsymbol{\xi}$ & $\begin{array}{c}\boldsymbol{f}_{\boldsymbol{s c}, \boldsymbol{d}} \\
\boldsymbol{f}_{\boldsymbol{s c}, \boldsymbol{o}}\end{array}$ & $\boldsymbol{\xi}$ & $\begin{array}{c}\boldsymbol{f}_{\boldsymbol{s} \boldsymbol{c}, \boldsymbol{d}} \\
\boldsymbol{f}_{\boldsymbol{s c}, \boldsymbol{o}}\end{array}$ \\
\hline Ding et al. 2016 [5] & & & & \\
\hline OST1-A & 0.32 & 1.00 & 0.31 & 1.00 & 0.35 & 0.88 \\
OST1-B & 0.33 & 1.00 & 0.32 & 1.01 & 0.36 & 0.86 \\
OST2-A & 0.52 & 1.00 & 0.51 & 1.05 & 0.57 & 0.90 \\
OST2-B & 0.52 & 1.00 & 0.50 & 1.04 & 0.57 & 0.84 \\
OST3-A & 0.22 & 1.00 & 0.22 & 0.95 & 0.25 & 0.86 \\
OST3-B & 0.23 & 1.00 & 0.23 & 0.95 & 0.26 & 0.86 \\
OST4-A & 0.36 & 1.00 & 0.35 & 0.99 & 0.39 & 0.91 \\
OST4-B & 0.36 & 1.00 & 0.35 & 0.99 & 0.40 & 0.88 \\
\hline Zhu and Chan (2018)[6] & & & & \\
\hline O-CF-1 & 0.25 & 1.00 & 0.25 & 0.98 & 0.28 & 1.00 \\
O-CF-2 & 0.25 & 1.00 & 0.25 & 0.95 & 0.28 & 1.00 \\
\hline
\end{tabular}

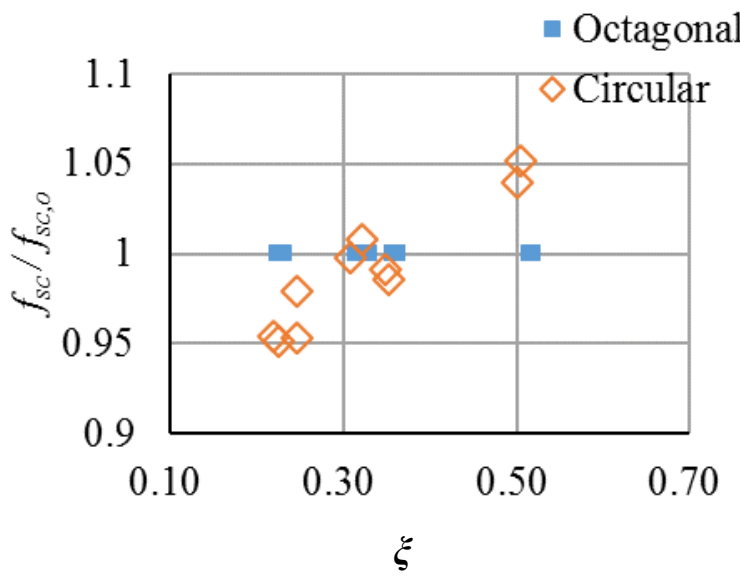

Fig. 2. Relationship of material contribution ratio and the normalized axial stress of the CFSTs with octagonal and circular sections.

\subsection{Comparison 3}

In this group, the control parameter is axial stiffness. Table 6 shows the results of comparison, which show very similar observation with that in comparison 2 . The confinement ratio is the crucial factor to the difference of performance between octagonal and circular CFST. To keep a same axial stiffness of the column, the square section may need a larger confinement ratio, but the axial bearing performance is still not as good as that in octagonal and circular CFST.

Table 6. Comparison between CFSTs with same axial stiffness.

\begin{tabular}{|c|c|c|c|c|c|c|}
\hline \multirow[b]{2}{*}{ Specimen } & \multicolumn{2}{|c|}{ OctCFST } & \multicolumn{2}{|c|}{ CCFST } & \multicolumn{2}{|c|}{ SCFST } \\
\hline & $\xi$ & $\begin{array}{l}f_{s c, o} / \\
f_{s c, o}\end{array}$ & $\xi$ & $\begin{array}{c}f_{s c, c} \\
f_{s c, o}\end{array}$ & $\xi$ & $\begin{array}{c}f_{s c, \mathrm{~d}} \\
f_{s c, o}\end{array}$ \\
\hline \multicolumn{7}{|c|}{ Ding et al. 2016 [5] } \\
\hline OST1-A & & 1.00 & .31 & 1.02 & 0.35 & 0.90 \\
\hline & & & & & & \\
\hline & & & & & & \\
\hline & 0.5 & 1. & & 1.06 & 0.58 & 0.84 \\
\hline & 0.2 & 1. & & 0.96 & 0.25 & 0.89 \\
\hline & & & & 0.96 & 0.26 & 0.89 \\
\hline & & & & & & 0.92 \\
\hline & 0.36 & 1.00 & & 1.03 & 0.40 & 0.93 \\
\hline \multicolumn{7}{|c|}{ Zhu and Chan (2017)[6] } \\
\hline & 0.25 & 1.00 & & 0.9 & 0.28 & 0.98 \\
\hline $\mathrm{O}-\mathrm{CF}-2$ & 0.25 & 1.00 & 0.26 & 0.94 & 0.28 & 0.9 \\
\hline
\end{tabular}

\section{Conclusion}

This paper presented comparative investigations on the axial bearing capacity of octagonal, circular and square CFSTs. The existing experimental data of load capacity in octagonal CFSTs were collected and based on the geometrical properties of the octagonal specimens corresponding circular and square cross-sections were generated under three control parameters, confinement ratio, crosssectional area and section axial stiffness. With those circular and square cross-sections, finite element models were established to provide the numerical solution of the load capacity for the three groups of comparisons. The results of the investigations show conclusions as follows:

1. With the same confinement ratio, the axial bearing capacity of octagonal and circular CFST are very similar and both have a better performance than square CFST, the enhancement is up to $20 \%$.

2. With the same cross-sectional area or axial stiffness, the difference of axial bearing performance in octagonal and circular CFST is related to the confinement ratio. With a higher level of confinement ratio, the performance of circular CFST are better than octagonal CFST. The square CFST has a very poor axial bearing performance compared with that in octagonal and circular CFST. 


\section{References}

[1] Sen HK. Triaxial stresses in short circular concrete filled tubular steel columns. RILEMConference, Cannes; 1972.

[2] Tomii M, Yoshimura K and Morishita Y. Experimental studies on concrete-filled steel tubular stub columns under concentric loading. Stability of structures under static and dynamic loads. ASCE 1977; 718-741.

[3] Xiao QG, Teng JG and Yu T. Behavior and modeling of confined high-strength concrete. Journal of Composites for Construction 2010; 14(3): 249-259.

[4] Susantha KAS, Ge H and Usami T. Uniaxial stress-strain relationship of concrete confined by various shaped steel tubes. Engineering Structures 2001; 23(10): 1331-1347.

[5] Ding FX, Li Z, Cheng S and Yu ZW. Composite action of octagonal concrete-filled steel tubular stub columns under axial loading. Thin-Walled Structures 2016; 107: 453-461.

[6] Zhu JY and Chan TM. Behaviour of polygonalshaped steel-tube columns filled with highstrength concrete. Proceedings of the Institution of Civil Engineers-Structures and Buildings, 2018; 171(2): 96-112.

[7] BS EN 1994-1-1: Eurocode 4: Design of steel and concrete structures, Part 1.1, General rules and rules for buildings. BSI, London, UK; 2004.

[8] Han LH, Yao GH and Zhao X. Tests and calculations for hollow structural steel (HSS) stub columns filled with self-consolidating concrete (SCC). Journal of Constructional Steel Research 2005; 61(9): 1241-1269.

[9] Ellobody E, Young B. and Lam D. Behaviour of normal and high strength concrete-filled compact steel tube circular stub columns. Journal of Constructional Steel Research 2006; 62(7): 706715.

[10] Thai HT, Uy B, Khan M, Tao Z and Mashiri F. Numerical modelling of concrete-filled steel box columns incorporating high strength materials. Journal of Constructional Steel Research 2014; 102: 256-265.

[11]Han LH, Yao GH, Tao Z. Performance of concrete-filled thin-walled steel tubes under pure torsion. Thin-Walled Structures 2007; 45(1): $24-$ 36.

[12] Tao Z, Wang ZB, Yu Q. Finite element modelling of concrete-filled steel stub columns under axial compression. Journal of Constructional Steel Research. 2013; 89: 121-31. 